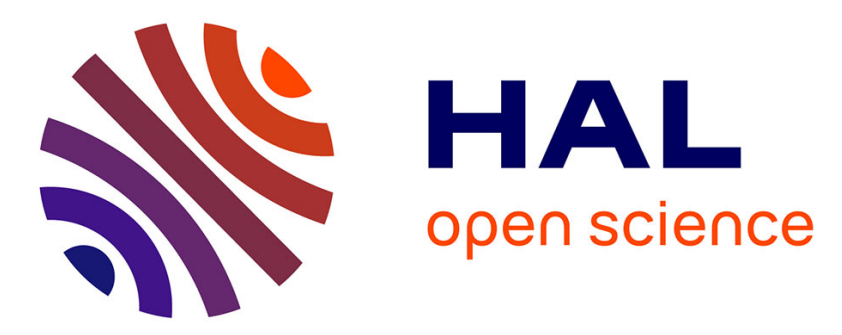

\title{
A simplified approach to determine the carbon footprint of a region: Key learning points from a Galician study
}

L. Roibás, Eléonore Loiseau, A. Hospido

\section{To cite this version:}

L. Roibás, Eléonore Loiseau, A. Hospido. A simplified approach to determine the carbon footprint of a region: Key learning points from a Galician study. Journal of Environmental Management, 2018, 217, pp.832-844. 10.1016/j.jenvman.2018.04.039 . hal-02015882

\section{HAL Id: hal-02015882 \\ https://hal.science/hal-02015882}

Submitted on 12 Feb 2019

HAL is a multi-disciplinary open access archive for the deposit and dissemination of scientific research documents, whether they are published or not. The documents may come from teaching and research institutions in France or abroad, or from public or private research centers.
L'archive ouverte pluridisciplinaire HAL, est destinée au dépôt et à la diffusion de documents scientifiques de niveau recherche, publiés ou non, émanant des établissements d'enseignement et de recherche français ou étrangers, des laboratoires publics ou privés. 
Author-produced version of the article published in Journal of Environmental Management, 2018, $\mathrm{N}^{\circ} 217$, p.832-844.

The original publication is available at https://www.sciencedirect.com/science/article/pii/S0301479718304213?via\%3Dihub Doi: 10.1016/j.jenvman.2018.04.039

\section{A simplified approach to determine the Carbon Footprint of a region: key learning points from a Galician study.}

Laura Roibás $^{1, *}$, Eléonore Loiseau ${ }^{2}$, Almudena Hospido $^{1}$

*Corresponding author. E-mail address: laura.roibas.cela@usc.es

1. Group of Environmental Engineering and Bioprocesses, Department of Chemical Engineering, Institute of Technology, Universidade de Santiago de Compostela, 15782 Santiago de Compostela, Galicia, Spain.

2. Irstea, UMR ITAP, ELSA Research Group for Environmental Lifecycle and Sustainability Assessment, 361 rue Jean-François Breton, 34196 Montpellier, France.

\section{Abstract}

On a previous study, the carbon footprint (CF) of all production and consumption activities of Galicia, an Autonomous Community located in the north-west of Spain, was determined and the results were used to devise strategies aimed at the reduction and mitigation of the greenhouse gas (GHG) emissions. The territorial LCA methodology was used there to perform the calculations. However, that methodology was initially designed to compute the emissions of all types of polluting substances to the environment (several thousands of substances considered in the life cycle inventories), aimed at performing complete LCA studies. This requirement implies the use of specific modelling approaches and databases that in turn raised some difficulties, i.e., need of large amounts of data (which increased gathering times), low temporal, geographical and technological representativeness of the study, lack of data, and presence of double counting issues when trying to combine the sectorial CF results into those of the total economy. In view of these of difficulties, and considering the need to focus only on GHG emissions, it seems important to improve the robustness of the CF computation while proposing a simplified methodology. This study is the result of those efforts to improve the aforementioned methodology. In addition to the territorial LCA approach, several InputOutput (IO) based alternatives have been used here to compute direct and indirect GHG emissions of all Galician production and consumption activities. The results of the different alternatives were compared and evaluated under a multi-criteria approach considering reliability, completeness, temporal and geographical correlation, applicability and consistency. Based on that, an improved and simplified methodology was proposed to determine the CF of the Galician consumption and production activities from a total responsibility perspective. This methodology adequately reflects the current characteristics of the Galician economy, thus increasing the representativeness of the results, and can be applied to any region in which 10 tables and environmental vectors are available. This methodology could thus provide useful information in decision making processes to reduce and prevent GHG emissions.

\section{List of abbreviations}

GHG, Greenhouse gas; LCA, Life Cycle Assessment; CF, Carbon Footprint; IO, Input-Output; UNFCCC, United Nations Framework Convention on Climate Change; EIO, Environmentally extended Input-Output; PA, process analysis; LCl, Life Cycle Inventories; US, United States; SRIO, Single-Region Input-Output; NAMEA, National Accounting Matrix with Environmental Accounts; WIOD, World Input Output Database; HT, Housing and Transport; FGS, Food, Goods and Services; NACE, Nomenclature statistique des Activités économiques dans la Communauté Européenne; MC, MultiCriteria; EPRTR, European Pollutant Release and Transfer Register. 
Author-produced version of the article published in Journal of Environmental Management, 2018, ํ217, p.832-844.

The original publication is available at https://www.sciencedirect.com/science/article/pii/S0301479718304213?via\%3Dihub Doi: 10.1016/j.jenvman.2018.04.039

\section{Introduction}

The average surface temperature of the Earth has risen since the mid-20 $0^{\text {th }}$ century, mainly caused by the anthropogenic increase in greenhouse gases (GHG) in the atmosphere (IPCC, 2013). This global warming phenomena is one of the most pressing environmental issues that humankind must address nowadays, as proved by the Paris Agreement (United Nations, 2015), a new global compromise aimed at holding global warming to well below 2 degrees Celsius above pre-industrial levels (i.e. 1850-1900 (Hawkins et al., 2017)).

This study focuses on Galicia, an Autonomous Community located in the north west of Spain, and whose average temperature has risen $0.20{ }^{\circ} \mathrm{C}$ per decade between 1961 and 2015, as found by a 2016 study of the Galician government, which evaluated data from 25 weather stations in the region (Xunta de Galicia, 2016). The regional government has the competencies to develop policy measures aimed at reducing and mitigating GHG emissions within the region (MAGRAMA, 2016), and it publishes periodic reports that present the GHG emissions of the region and evaluate their effects on the climate and the ecosystems.

The socio-economic characteristics of Galicia, in which the primary sector has traditionally been of high economic relevance, will affect the GHG emissions of the region. Regarding the production activities, the density of the bovine livestock sector (in heads per hectare) is 63\% higher in Galicia than in the rest the country (Eurostat, 2017; IGE, 2015). Moreover, Galicia is one of the Spanish regions with the highest electricity production (producing $1.08 \mathrm{GWh} / \mathrm{km}^{2}$ and doubling the Spanish average), but also one having a cleaner energy mix (in 2014, 60\% of the electricity came from renewable sources in Galicia, while on an average Spanish region they only reached $43 \%($ REE, 2014)). Finally, Galicians consume many products of animal origin (e.g., meat and milk consumption in households is respectively $21 \%$ and $15 \%$ higher than in the rest of Spain (INE, 2014)).

The GHG inventories published by the Galician government are downscaled from the Spanish inventories, published yearly by the Spanish government, as a party of the United Nations Framework Convention on Climate Change (UNFCCC). Thus, the Galician GHG inventories available only include the direct emissions that take place in the region, and may be subject to inaccuracies due to the downscaling procedure followed.

A holistic perspective, in which all the life cycle emissions linked to the region are accounted for, can provide a more complete knowledge of the total environmental impacts that the region is ultimately responsible for by identifying pollution transfers between territories, and lead to more effective decision making. To calculate the life cycle emissions of a certain region, three main approaches can be followed (Wiedmann, 2009a): i) a bottom-up strategy, based on process analysis $(\mathrm{PA})$, in which the impacts of individual products are added up to obtain the total impacts of the activities of a certain area; ii) a top-down strategy, based on environmentally extended input-output tables (EIO), which reflect the interactions among different sectors and relate environmental impacts to economic values; and iii) a hybrid approach, in which both strategies are combined.

The total GHGs of both Galician consumption and production activities were calculated following a life cycle perspective (Roibás et al., 2017), and then combined into a single indicator, the carbon footprint (Weidema et al., 2008), expressed in $\mathrm{CO}_{2}$ equivalents. To do so, a hybrid approach based on territorial LCA (Loiseau et al., 2013) was used. This hybrid methodology combines a bottom-up with a top down approach (based in the 2002 United States Environmental Input Output -US EIO- database), to evaluate the total environmental impacts of all the production and consumption activities that take place within a region. Territorial LCA applies a total responsibility approach (Eder and Narodoslawsky, 1999), in which all upstream activities related to local production and consumption are accounted for, whether or not they are located within the Galician region.

When calculating the CF of both the Galician consumption and production activities using territorial LCA, the authors encountered some limitations. Territorial LCA was initially designed 
to compute the emissions of all types of polluting substances to the environment (several thousand of substances including GHG) to perform complete LCA studies. This requirement implies the use of specific modelling approaches and databases that in turn raised some difficulties that seem to be worthless for computing only one category of impacts, i.e. carbon footprint. On the one hand, the suitability of using process LCA was questioned, due to the cutoffs that are inherent to that methodology, to the large amount of time invested in data gathering (which would hinder the replicability of the study in this or other regions), and to the need to fill certain data gaps (e.g. Spanish data was used when Galician data was unavailable). On the other hand, it was acknowledged that the use of an outdated US EIO database in a European study may have affected the geographical, temporal and technological representativeness of the study. Thus, it was concluded that further research involving different calculation approaches (i.e. different top-down approaches based on more suitable IO databases) should be carried out, both to improve the accuracy of the Galician CF results and to propose a simplified methodology to be followed in subsequent studies in this or other regions.

This paper presents the results of the aforementioned required further research, in which several methodological alternatives have been evaluated to determine the CF of the Galician production and consumption activities. The objective of this study is to improve the accuracy of the available CF results, while simplifying the methodology used for their calculation, in order to increase its applicability in subsequent studies in Galicia or other regions.

After this first introductory section, the study is structured in the following ones: the second section presents the different methodological alternatives used to determine the CF of both Galician consumption and production and the analysis grid built to compare them; the third section presents and discusses the results of these alternatives, proposes a recommended methodology for future studies, evaluates its quality and compares its results to those in the literature. The last section draws the general conclusions of the study.

\section{Materials and methods}

The aim of this paper is to reach a compromise between the high representativeness of the results and the simplification of the calculation procedure. This section describes the procedure followed to do so: several calculation alternatives are presented in the first subsection, and the criteria for their comparison are defined in the second one.

\section{Description of the alternatives}

The CF computation relies on combining activity descriptors with Life Cycle Inventories (LCI). The activity descriptors are economic values or physical quantities that describe the Galician consumption (e.g. the number of kilometres travelled by car, or the household expenditures in road transport), while the $\mathrm{LCl}$ relates these descriptors to a certain amount of GHG emissions. These $\mathrm{LCl}$ can be taken from two types of databases: PA databases such as Ecoinvent, or EIO databases, in which the $\mathrm{LCl}$ are a result of combining environmental vectors with input output matrixes.

This section details the methodological procedures followed to determine the CF of the Galician production and consumption activities. The first subsection presents the different sources of LCls considered, and the following two include a more detailed explanation on how these $\mathrm{LCls}$ have been combined with the activity descriptors to determine the CF of both consumption and production.

2.1.1. Overview of the $\mathrm{LCl}$ databases considered

This section presents the different $\mathrm{LCl}$ databases that have been considered to determine the CF of the Galician consumption and production activities. In the original territorial LCA approach (Roibás et al., 2017), PA and the US EIO database were used, and so their LCI data sources are presented first. All the alternatives considered here are based on EIO databases, which are presented afterwards. 
When using PA, the main sources of $\mathrm{LCl}$ were the following: i) regional inventories, taken from Galician LCA studies, when available; ii) the Ecoinvent database v3.1 (Wernet et al., 2016), the most complete $\mathrm{LCl}$ database available; iii) the Agribalyise database (Colomb et al., 2015), used for those agricultural products not included in the previous one; iv) other LCl studies published in the literature, when the required data was not available in any of the previous sources.

The US EIO database (Suh, 2010) was used in the original territorial LCA methodology due to its completeness: it contains 480 sectors of activity and more than 1300 substances including 44 GHG. It is, however, a single-region input-output database (SRIO), which means that it only contains data regarding one country (the US in this case), and thus it implies that each product is obtained with the US technology (and emissions) regardless of its country of origin. Last, regarding its applicability, it is implemented in the SimaPro software, and so it is easy to use for LCA practitioners.

The first alternative database considered in this study is the Galician Input-Output matrix MIOGAL (IGE, 2011)-, which is a 2011 SRIO matrix that includes 71 sectors and that can be downloaded from (IGE, 2017). This matrix, however, does not contain environmental data, so this information has been taken from the Spanish NAMEA (National Accounting Matrix with Environmental Accounts) air set. This dataset contains the yearly GHG emissions of the Spanish economic sectors (INE, 2016b), which have been expressed per unit of economic output (INE, 2016a), to obtain the Spanish GHG vector, which was assumed representative of the Galician conditions. This vector corresponds to 2012, the most recent year for which all required data were available. The resulting matrix contains 71 sectors and $6 \mathrm{GHG}$. Due to its small size, all the calculations can be done using Excel.

As a second option, the World Input Output Database -WIOD (Timmer et al., 2015)- has been used. This is a 2011 multi-region IO database (MRIO) that contains data for 41 countries including Spain. WIOD includes 35 sectors of activity, and its environmental vector contains 3 GHG and corresponds to 2009. The matrix can be downloaded from (WIOD, 2013b), and the environmental vector for each country from (WIOD, 2013a).All data are available in Excel format and thus calculations can be performed using Excel.

The last option considers another MRIO database, Exiobase (Tukker et al., 2013; Wood et al., 2015). This 2007 database is more complete than the WIOD database: It includes 48 countries, 163 sectors and $5 \mathrm{GHG}$. Although it is available in Excel format, the larger size of the matrix makes impossible calculating CF values with Excel, and thus Anaconda Python (Anaconda Software Distribution, 2016) has been used to process these data.

The last two options contain Spanish data, and thus they imply assuming that both the Galician technology (and its emissions) and its consumption patterns are equal to those of Spain. Although this assumption can imply a loss of reliability, both alternatives have still been considered since they use more recent data than the original methodology and also MRIO databases, expected to provide more accurate results when compared to SRIO matrixes (Wiedmann, 2009b).

Each alternative considered has different geographical and temporal coverages, and a different amount of substances and sectors included. These and other parameters have been used to compare them following a multi-criteria analysis (see section 2.2).

2.1.2. Alternatives for Galician consumption activities

The Galician consumption is structured into 5 categories, i.e., food, goods, services, transport and housing (Loiseau et al., 2012). The sectors included in the Galician IO matrix, WIOD and Exiobase have been split among the categories as shown in section S1 of the supplementary material. Besides, the CF only covers inhabitant consumption as (Roibás et al., 2017) recently showed that tourist contribution is not significant.

In this study, PA has been only used to determine the CF of housing and transport, since the lack of data impedes its application to the remaining categories, whereas the four different EIO databases can be used for all categories. So, the results will be presented here in a separate manner (Figure 1), differentiating the housing and transport categories (HT) from the 
Author-produced version of the article published in Journal of Environmental Management, 2018, N²17, p.832-844. The original publication is available at https://www.sciencedirect.com/science/article/pii/S0301479718304213?via\%3Dihub Doi: 10.1016/j.jenvman.2018.04.039

remaining three (FGS). The alternatives have been named HT_N and FGS_N, with $\mathrm{N}$ varying from 1 to 5 for the former and from 2 to 5 in the latter, to guarantee the relationship among $\mathrm{LCl}$ data sources.

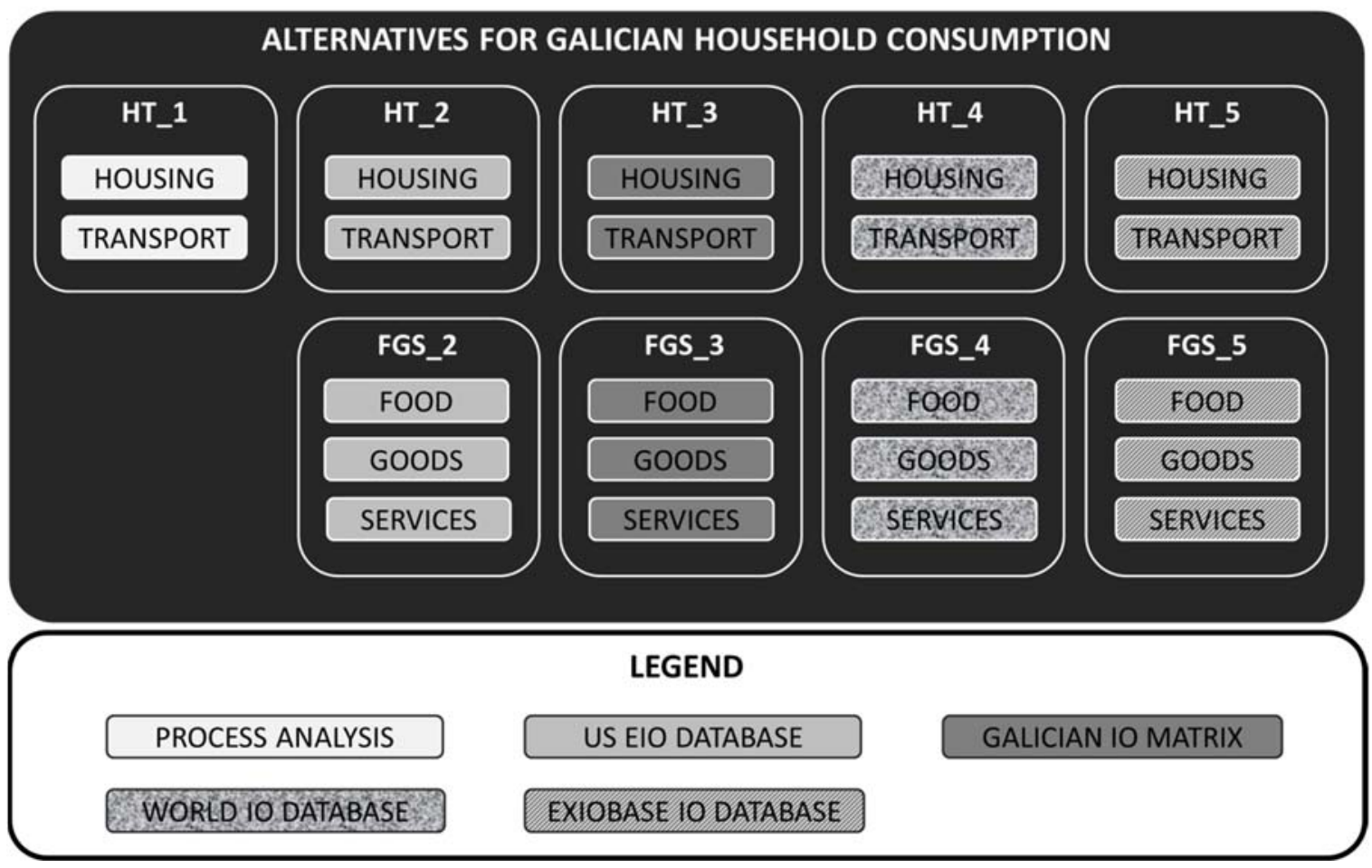

Figure 1: Schematic description of the categories and alternatives considered for consumption.

To obtain the CF of the HT_1 group, the activity descriptors (such as the amount of kilometres travelled per person and year, or the annual electricity consumption in households per capita) have been combined with the LCls mentioned in section 2.1.1 for process analysis, using the SimaPro software. A complete list of the activity descriptors used and the $\mathrm{LCl}$ data can be found in S2. It should be noted that the LCl inventories used to evaluate alternative HT_1 have been modified to exclude the purchased items that have already been accounted for in the FGS group, so as to avoid double counting. For instance, the manufacture of the fuel used to propel particular vehicles has been excluded from the transport category, since its purchase has already been accounted for in the goods category.

The procedure followed to determine the CF of consumption for those alternatives based in 10 matrixes (alternatives 3 to 5 ) is detailed in the next paragraph. This procedure was not necessary when using the US EIO database (alternative 2), since this database is implemented in SimaPro. Thus, to evaluate the second alternative, the expenditure data of the Galician households (INE, 2014) were used as the activity descriptors, combined with the items of the US EIO database according to a correspondence table, as further detailed in section S3 of the supplementary material.

The CF calculation is based on the input-output (IO) model developed by Leontief (1951), and described in eq.1, where $\mathrm{C}^{\text {hh,cons }}$ is the vector of total (direct plus upstream) GHG emissions caused by household consumption. The first term of eq. 1 computes all embodied emissions caused by $y_{h}$, the final demand of households, based on $A$, the intermediate demand matrix. $A$ is defined such that each column shows the intermediate industry input that is required to produce one unit of output, and $B$ is the vector of environmental interventions, which shows the amount of GHGs emitted to produce one unit of monetary output of each industry. The second term, $C^{d}$ refers to direct emissions caused by households.

$$
C^{\text {hh, cons }}=B(I-A)^{-1} y_{h}+C^{d}
$$


Author-produced version of the article published in Journal of Environmental Management, 2018, N²17, p.832-844. The original publication is available at https://www.sciencedirect.com/science/article/pii/S0301479718304213?via\%3Dihub Doi: 10.1016/j.jenvman.2018.04.039

It should be noted that the direct emissions caused by households $\left(C^{d}\right)$ are not available in the Galician statistics. The $C^{d}$ value is available both in WIOD and Exiobase databases, and it contains direct household emissions for Spain and for the remaining countries included in both MRIO databases. However, neither the Galician MIOGAL database, nor the US EIO one contain data about household emissions, and thus they have been added manually taken from Spanish statistics (INE, 2013), due to the absence of Galician data.

When using MRIO tables (alternatives 4 and 5), the A matrix is constituted of numerous submatrixes that represent the interactions between different countries (Peters, 2008), and y and $B$ are computed for each country.

When using SRIO matrixes such as the Galician IO matrix (alternative 3), all this information is not available, and thus a "domestic technology assumption" is required (Wiedmann, 2009b), meaning that the imported products are produced in other countries by the same intermediate product use and by the same environmental intensities as in domestic production.

\subsubsection{Alternatives for Galician production activities}

The production activities have been divided among eight sectors following the European Union official classification of economic activities, called NACE (Rev. 2) (Eurostat, 2008): primary sector, quarrying, energy, building, manufacturing, transport, services and end of life (EOL) activities. As done for consumption, the production sectors have been grouped into two categories according to the calculation alternatives considered (Figure 2).

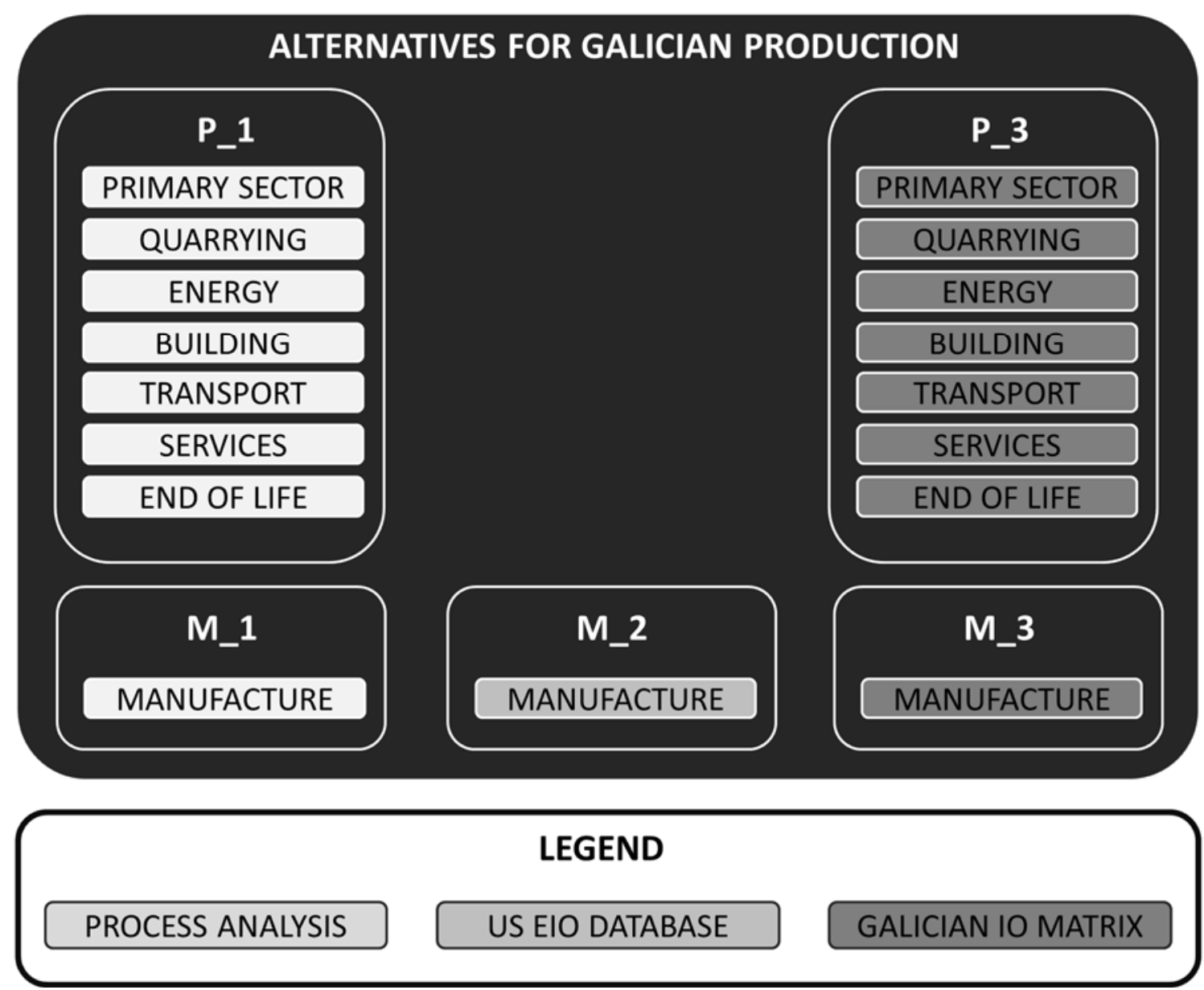

Figure 2: Schematic description of the categories and alternatives considered for production.

The CF of Manufacturing (the largest contributor to the total CF in the original study) has been calculated following three alternatives (named M_1 to M_3) and the corresponding Production with only two (P_1 and P_3). Using any of the MRIO tables to determine the CF of the Galician 
production has been discarded, since they represent the Spanish production conditions and their direct use would yield the CF of the 2011 Spanish production, much higher than the Galician one. Moreover, adapting the matrixes to substitute Spanish data by Galician data has been discarded, due to the large size of the matrixes which would imply very long downscaling processes. Regarding SRIO tables, only the Galician IO matrix has been used to determine the CF of all the sectors, while the use of the US EIO database has been restricted to the manufacturing sector, since this was the alternative used in the previous study (Roibás et al., 2017). Using the US EIO database to calculate the CF of the remaining Galician production sectors (i.e. calculating P2) was also avoided, since the use of this outdated, foreign database is one of the drawbacks of the previous study that this one tries to amend.

When using the Galician 10 matrix to determine the CF of each of the Galician production sectors (alternatives $P_{-} 3$ and M_3), Eq.2 has been used (Peters and Hertwich, 2006):

$$
C^{\text {prod }}=B(I-A)^{-1}\left(y^{G G}+e^{G R}\right)
$$

Where the $A$ matrix is the intermediate demand matrix, $B$ is the vector of environmental interventions, $y^{G G}$ represents the Galician final demand of Galician products and $e^{G R}$ represents the exports of Galician products to the remaining regions R. This alternative allows accounting for the life cycle emissions of all the Galician products, regardless of where they are consumed. Process analysis is used to determine the CF of the manufacturing sector in M_1 alternative. To do so, only the CFs of those companies listed on the European Pollutant Release and Transfer Register (EPRTR, (PRTR España, 2015)), have been taken into account. Data of the annual production of each company has been taken from that Register (when available), and otherwise from the companies, which were contacted by phone and/or e-mail. These data of annual production were used as the activity descriptors in M_1 alternative. All data sources and inventories used are detailed in section $\mathrm{S} 4$ of the supplementary material.

PA was also used to determine the CF of the remaining sectors in P_1 alternative. To do so, data about their annual outputs was gathered (e.g. the annual production of each culture in the agricultural sector, the amount of each mineral extracted annually in the quarrying sector...), and used as activity descriptors. All data sources can be found in S5 of the supplementary material. However, one major exception had to be done to this procedure: for the services sector, only the annual electricity, heat and water consumption was accounted for, due to the lack of data.

To obtain the CF of the Galician manufacturing sector following M_2 approach, the annual output of the different subsectors of the Galician manufacturing has been used, as detailed in section $\mathrm{S} 6$ of the supplementary material.

It should be noted that there is an important methodological difference between PA based alternatives ( $P_{-} 1$ and $M_{-} 1$ ) and 10 based ones ( $M_{-} 2, P_{-} 3$ and $\left.M_{-} 3\right)$, which affects the comparability of their results, due to the different system boundaries considered. While the PA based alternatives apply the territory principle, i.e. they include the emissions of all the activities located within the territory, the 10 based alternatives follow the resident principle, thus including all the emissions of resident economic units, even if these occur outside the territory. More information about both principles can be found in Eurostat (2016). Even though both approaches are correct as long as they are applied in a consistent way, their results may be different for some of the categories considered (see section 3.2).

2.1.4. Handling double counting between production activities

It should be noted that when following all the aforementioned alternatives, with the exception of those based on the Galician IO matrix (P_3 and $M_{-}$3), double counting issues may arise when combining the environmental impacts of the different activities. Once the CF of each sector has been obtained, the total CF of all the Galician production cannot be calculated by just summing up the results of all the sectors, since that would imply double counting of goods that are produced in the region and used as raw materials in other local production activities. For instance, Galician minerals that are used in the Galician energy sector would be accounted for twice, both in the quarrying and in the energy sector (Lenzen, 2008). A procedure based on 
the Galician IO matrix has been followed to avoid this double counting, as detailed in (Roibás et al., 2017). This approach has been applied to alternatives P_1, M_1 and M_2.

In summary, the procedure is based on a consumer responsibility principle, thus assuming that for Galician activities belonging to the same supply chain, impacts are allocated to the most downstream activity in the chain. In the example used above, the energy sector would be responsible for the GHG emissions incurred by the extraction of the minerals it consumes, which would not be accounted for in the Galician quarrying impacts. Thus, for each sector, only the share of its CF that is not used as a raw material in the remaining Galician sectors was accounted for, using data from the Galician 10 matrix. In the case of the quarrying sector, only the impacts of the minerals which are exported to other regions or consumed in households are accounted for, since the rest of them are already considered in other Galician supply chains (such as the energy one).

\subsubsection{Summary of assumptions}

As already mentioned, using each of the alternatives to determine the CF of both Galician consumption and production implies some assumptions. This assumptions are organised and further detailed in section S7 of the supplementary material.

\section{Defining key criteria for comparing the alternatives}

The criteria chosen for the Multi Criteria (MC) analysis have been inspired by the pedigree matrix of Weidema and Wesnæs (1996), which has been used in numerous studies to evaluate data quality (Gallego et al., 2009; Weidema, 2013). In this case, however, the criteria have been slightly modified and combined into a final score, as detailed below.

The original pedigree matrix contains five criteria (Weidema and Wesnæs, 1996): i) reliability, ii) completeness, iii) temporal correlation, iv) geographical correlation and v) further technological correlation. The four first criteria have been used here, while the fifth one has been excluded. The last criterion refers to the technological differences that may exist among the actual production processes (in Galicia) and those modelled in the $\mathrm{LCl}$ data, other than those originating from the different temporal and geographical framework. The macroeconomic character of this study, in which very broad consumption and production categories have been included and IO-based LCls are used, makes almost impossible identifying the differences in production technologies considered, other than those reflected by the temporal and geographical variability already accounted for in criteria iii and iv. Instead, and since one of the objectives of the study is to simplify the original methodology, a fifth criterion reflecting the applicability of the alternatives has been included, to evaluate the ease of application of each alternative and the usefulness of its results. Last, and since double counting issues had to be solved in some of the alternatives while in others they do not appear, a consistency criterion has also been added to reward the absence of double counting issues. The alternatives evaluated will be given a score from 1 to 5 , from the least to the most representative of the actual conditions (1: very poor; 2: poor; 3: average; 4: good; 5: very good). The six criteria chosen and a more specific description of the scores considered are detailed below:

i) Reliability of the results: In the original pedigree matrix, this criterion related to the sources, acquisition methods and verification procedures used to obtain the inventory data. Since the all the $\mathrm{LCl}$ data used are taken from databases (either PA or IO databases) and there is a wide variety among the data sources used in each of them and even among their different inventories, this criterion has been slightly modified to refer to the overall reliability of the different methodologies used. The results obtained with each alternative will be compared to one another (sections 3.1 and 3.2) and those alternatives which present relevant deviations from the remaining ones in some categories will be assigned lower scores. It is difficult to separate this criterion from the following ones (e.g. a lower level of completeness of a certain alternative can 
cause an important underestimation of its results, and thus that alternative would be penalized twice). However, and since one of the objectives of the paper is to increase the accuracy of the results, the authors believe that this criterion should stay even if it overlaps some of the remaining ones. A score will be assigned to each alternative based on their results of the CF of consumption, while the results of production will not be considered here for two reasons: i) the EIO based and PA based alternatives may yield very different results for production, but these differences respond only the use of different system boundaries (territory principle versus resident principle); ii) only 3 alternatives have been considered for production.

ii) Completeness: This criterion evaluates the representativeness of the data. As detailed before, to perform the calculation, the activity descriptors need to be combined with the $\mathrm{LCI}$. Thus, this criterion has been split here as follows:

a. Completeness of the activity descriptor: This criterion reflects the data gaps encountered when defining the alternative descriptors. This is a matter affecting mainly PA alternatives, in which some sectors have not been fully evaluated due to the lack of data (e.g. services sector). Thus, PA based alternatives receive the lowest score in this category (1). The US EIO based alternatives start from Galician expenditure figures (for consumption), and productive output (for production). Even though both datasets were rather descriptive and complete, assumptions were required for data conversion to the required categories (see sections S3 and S6 of the supplementary material), and thus an average score is awarded to these alternatives (3). It is difficult to identify data gaps in the remaining 10 based alternatives, since expenditure data is available for all the categories considered, at the level of detail required by each methodology. This means that data gaps were solved when creating the 10 matrixes, and thus the highest score (5) is awarded to them.

b. Completeness of the $\mathrm{LCl}$ : Since the $\mathrm{LCl}$ combines inventory tables (or 10 matrixes) with GHG data (or emission vectors), this criterion has been further subdivided:

1. Completeness of the inventory table: This criterion evaluates the alternatives in terms of the completeness of the inventory table. PA based alternatives receive the lowest score (1), since they are affected by cut-offs. Single-region 10 alternatives receive average scores (3), while multi-region alternatives, the most representative ones, are awarded the highest score (5).

2. Completeness of the environmental data: This criterion is related to the number of GHG included in each $\mathrm{LCl}$. The higher the number, the higher the score. When only $\mathrm{CO}_{2}$ is accounted for, the alternative gets the lowest score (1). When a database considers 3 to $5 \mathrm{GHGs}$, an average score is applied (3). More complete databases, considering from 6 to 9 GHGs are awarded a higher score (4), while those including more than $10 \mathrm{GHGs}$, get the highest one (5).

iii) Temporal correlation: This criterion represents the time correlation between the year of the study and the year of the data used. Since the objective of this study is to obtain the most updated CF results, the level of updating of the datasets used has been evaluated here. Thus, scores have been assigned according to the age of the data: 5 points are given to 2014 or newer data, 4 for data belonging to the period 2011-2013; 3 for 2008-2010; 2 for 2005-2007; and 1 for 2004 or older. Two main sub criteria are considered: 
a. Updating of the activity descriptors: The activity descriptors used correspond to the most recent year available, but these years are variable among the different alternatives.

b. Updating of the LCls: This sub criteria evaluates how recent the inventories used are. Again, this criterion has been further subdivided:

1. Updating of the inventory table: The criterion reflects the age of the inventory data used.

2. Updating of the environmental data: Reflects the age of the environmental vector used, which for some databases is different from that of the matrix.

iv) Geographical correlation: Similar to the previous one, it reflects the geographical correlation between the area under study (Galicia) and the data used. The following scores have been considered here: 5 when Galician data was used; 4 for Spanish data; 3 for European data (Ecoinvent); 1 for US data. Like the previous one, this criterion is divided among the next sub criteria:

a. Geographical correlation of the activity descriptors, which indicates if the activity descriptors used correspond to Galician statistics or have been taken from other regions.

b. Geographical correlation of LCls: This criterion indicates if the $\mathrm{LCl}$ data used reflect the Galician reality or have been taken from other regions. Again, this criterion is split in two:

1. Geographical correlation of the inventory table.

2. Geographical correlation of the environmental data.

v) Applicability: It refers to the applicability of the alternatives, both in terms of the calculation procedure and of the usefulness of the results. Thus, it has been further divided as follows:

a. Applicability of the methodology: It aims at rewarding the ease of application of each method, seeking to facilitate the spreading of the proposed methodology. It has been evaluated in terms of:

1. Data gathering requirements: This criterion evaluates the amount of data required to calculate the CF with each alternative. PA based alternatives require large amounts of data (whose gathering is very time consuming) while the 10 based alternatives are based on data which is very accessible. Thus, PA alternatives get the lowest score (1) and $I O$ based ones the highest (5).

2. Software/training requirements: This criterion evaluates the type of software required in each alternative, and also its simplicity (i.e. if trained personnel are required). A 5 score has been given to the Excel software, the simplest possible; a 3 has been awarded to LCA software -such as SimaPro-, which are not as simple but are frequently used by LCA researchers; and last, a 1 has been given to more complex software, such as Anaconda Python, which would require specific training.

3. Economic requirements: Linked to the previous one, this criterion evaluates the cost (if any) of the databases and software used. Free alternatives get the highest score (5), while those requiring expenditures are given the lowest rate (1).

4. Calculation time requirements: Last, this criterion evaluates the computational times required to apply the proposed methodologies (once all required data is available), which have been ranked from 1 (the longest) to 5 (the shortest). 
b. Applicability of the results: This criterion reflects the usefulness of the results for policy makers. The higher the number of activity descriptors used, the more applicable the results are, since knowing the particular processes that are responsible for a certain emission allows more effective decision making, and so the specificity of the activity descriptors used in each alternative is evaluated here.. In practice, PA has been given a 5 score in this category, while the remaining 10 databases are ranked according to the number of sectors they include (4 for 480 sectors; 3 for 163 sectors; 2 for 72 sectors and 1 for 35 sectors).

vi) Consistency: Since the methodology is aimed at evaluating the total CF of a certain territory, the avoidance of double counting issues is a relevant feature that needs to be evaluated. Even though double counting has been avoided in all the alternatives considered (it does not occur in alternatives 3 to 5 and it has been solved for alternatives 1 and 2 as shown in section 2.1.3.1), a highest score must be awarded to those alternatives that allow avoiding double counting when used alone (5) when compared to the remaining ones (3). If double counting issues were still present for a certain alternative, the lowest score would be assigned (1).

All six criteria have been assigned the same weight, which in turn has been equally split among the existing subcriteria. This choice responds to the difficulty in estimating the relative influence of each criterion in the representativeness of the results. In any case, different weighting procedures could be considered in subsequent studies, as long as they are stated in a transparent way.

\section{Results and discussion}

This section displays the CF results obtained for both Galician consumption and production activities, according to the different alternatives defined. The results are compared to each other, and the possible sources of the differences found are discussed according to the criteria defined. Finally, a score will be given to each alternative and an improved methodology will be proposed based on this multi-criteria analysis.

\section{Carbon Footprint of consumption}

As detailed in section 2.1.2, the CF of the consumption activities has been split into two groups according to the type of good consumed: housing and transport (HT) on the one hand; and food, goods and services (FGS) on the other hand. The results of both groups are analysed separately here.

It should be noted that the IO-based alternatives considered start from different figures of household expenditures (i.e. activity descriptors), since all of them come from different sources and correspond to different regions (Table 1). These differences can help explaining the variability of the CF results, and therefore they are reported here before proceeding to analyse the results.

The information contained in Table 1 is self-explanatory with the exception of the "Year" column, which is further divided into three subcategories: the first one ("Cons") reflects the year to which the activity descriptor (household expenditures) is referred; the second one (Environmental, indirect) refers to the date of the environmental vector, which depends on the EIO database used; the last one (Environmental, direct) reflects to which year the direct household emissions ( $C^{d}$ term of Eq.1) are referred.

Table 2: Household expenditures and main characteristics of the data used in each alternative.

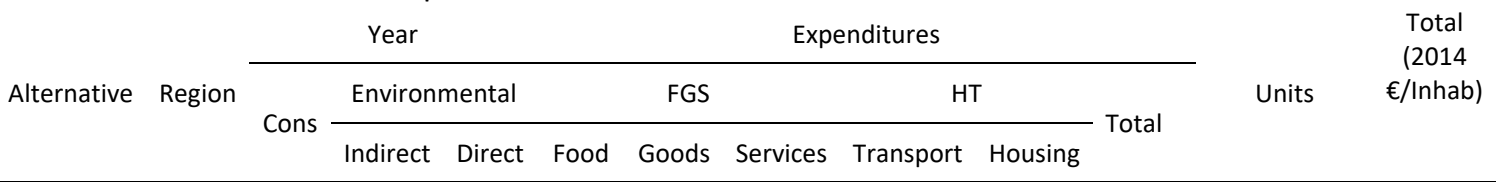


Author-produced version of the article published in Journal of Environmental Management, 2018, ํ217, p.832-844. The original publication is available at https://www.sciencedirect.com/science/article/pii/S0301479718304213?via\%3Dihub Doi: 10.1016/j.jenvman.2018.04.039

\begin{tabular}{lllllllllllll}
\hline 2 & Galicia & 2014 & 2002 & 2013 & 1,968 & 2,232 & 2,910 & 72 & 3,009 & 10,190 & $2014 € /$ Inhab & 10,190 \\
3 & Galicia & 2011 & 2012 & 2011 & 1,313 & 1,127 & 6,533 & 225 & 2,231 & 11,430 & $2011 € /$ Inhab & 11,990 \\
4 & Spain & 2011 & 2009 & 2009 & 1,553 & 1,956 & 7,087 & 385 & 2,143 & 13,124 & $2011 € /$ Inhab & 13,767 \\
5 & Spain & 2007 & 2007 & 2007 & 1,283 & 1,772 & 6,746 & 360 & 1,967 & 12,128 & $2007 € /$ Inhab & 13,959 \\
\hline
\end{tabular}

The CF of both groups of consumption activities are shown below (Figure 3 ), and the analysis of the results will be presented separately for the HT and the FGS group. For each of them, the most reliable alternative(s) to evaluate each category are mentioned below, while more detailed information about the logics followed to reach those conclusions can be found in section $\mathrm{S} 8$ of the supplementary material.

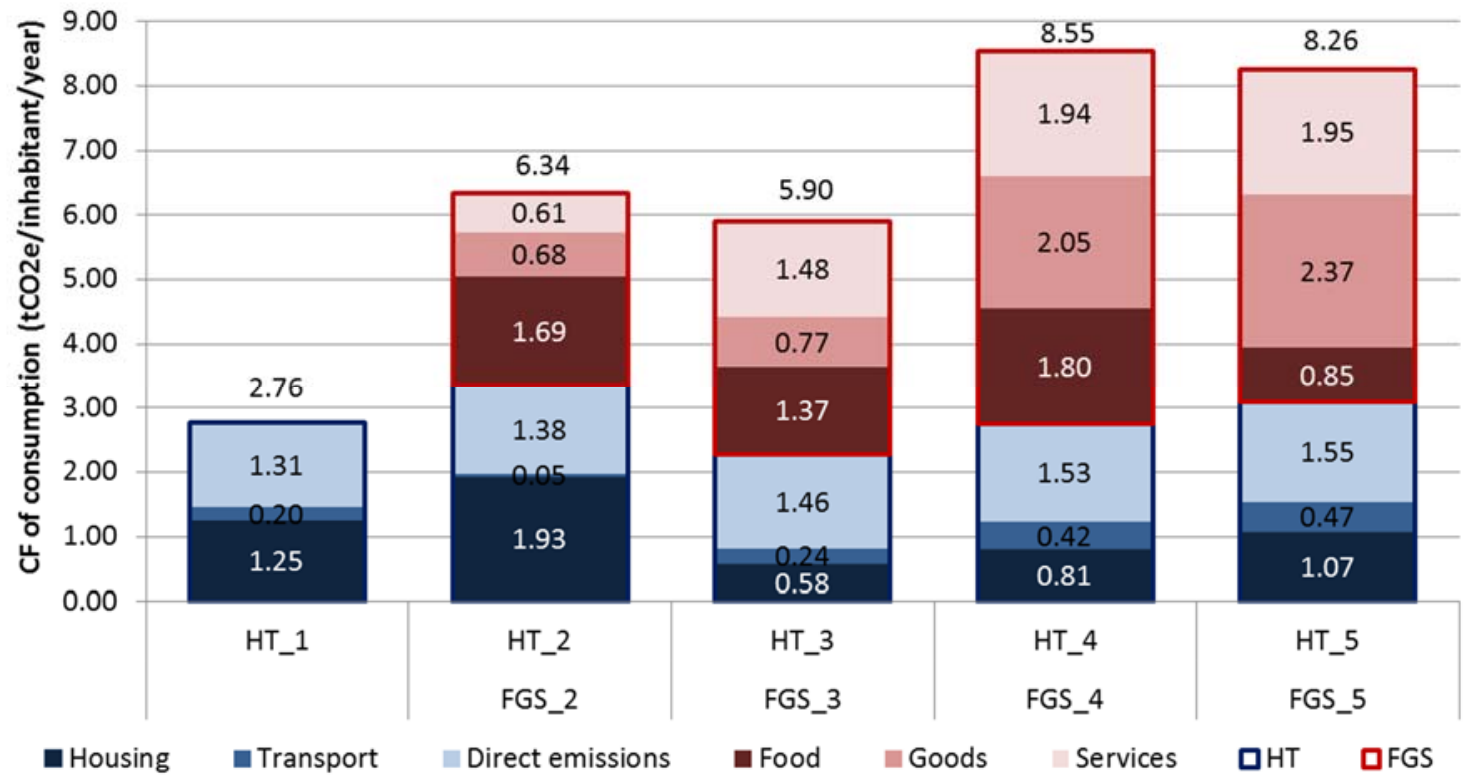

Figure 3: Carbon footprint of the yearly consumption of a Galician inhabitant.

For the housing and transport consumption categories, the three main contributing items are shown in Table 2. The first alternative is the only one based on process analysis, while the remaining ones are taken from IO studies (see figure 1). Thus, the CF of HT_1 (Housing and Transport activities evaluated with alternative 1) has been calculated with SimaPro. When doing so, the direct emissions from housing and transport were separated from the indirect ones, so as to be consistent with the remaining alternatives evaluated. For the remaining alternatives (HT_2 to HT_5), this direct emissions have been directly taken from the sources detailed in section 2.1.2 for $\mathrm{C}^{\mathrm{d}}$. 
Table 2: Major contributors to the CF of housing and transport in each alternative.

\begin{tabular}{|c|c|c|}
\hline Alt. & Housing & Transport \\
\hline HT_1 ${ }^{a}$ & $\begin{array}{l}\text { - Heat }(38 \%) \\
\text { - Electricity (36\%) } \\
\text { - Building }(17 \%)\end{array}$ & $\begin{array}{l}\text { - Ground transport (61\%) } \\
\text { - Rail transport }(20 \%) \\
\text { - Air transport (14\%) }\end{array}$ \\
\hline HT_2 & $\begin{array}{l}\text { - Electricity }(77 \%) \\
\text { - Natural gas (10\%) } \\
\text { - Water supply and sewage (4\%) }\end{array}$ & $\begin{array}{l}\text { - } \text { Air transport }(51 \%) \\
\text { - } \text { Ground transport (38\%) } \\
\text { - } \text { Rail transport (11\%) }\end{array}$ \\
\hline HT_3 & $\begin{array}{l}\text { - Supply of electricity and gas (74\%) } \\
\text { - Building (12\%) } \\
\text { - } \text { Real estate activities (8\%) }\end{array}$ & $\begin{array}{l}\text { - Terrestrial transport (81\%) } \\
\text { - Air and sea transport (19\%) }\end{array}$ \\
\hline HT_4 & $\begin{array}{l}\text { - Electricity, gas and water (81\%) } \\
\text { - Real estate }(10 \%) \\
\text { - Construction }(9 \%)\end{array}$ & $\begin{array}{l}\text { - Inland transport (55\%) } \\
\text { - Air transport (40\%) } \\
\text { - Water transport (5\%) }\end{array}$ \\
\hline HT_5 & $\begin{array}{l}\text { - Production of electricity (55\%) } \\
\text { - Real estate activities (16\%) } \\
\text { - Manufacture of gas; distribution of gaseous fuels (14\%) }\end{array}$ & $\begin{array}{l}\text { - Air transport (40\%) } \\
\text { - Land transport: railway, pipelines and } \\
\text { other land transport (38\%) } \\
\text { - Water transport: inland and sea (22\%) }\end{array}$ \\
\hline
\end{tabular}

${ }^{a}$ Only indirect emissions are included here, for consistency.

The results of housing show high variability among the alternatives (figure 3 ) When looking at its individual contributors, the higher CF of housing obtained with HT_2 has two origins: the higher expenditure data considered in that category (table 1), and the high contribution of electricity supply due to the use of the US EIO database. Thus, HT_2 probably overestimates the CF of housing when compared to the remaining alternatives. On the other hand, HT_1 is the only alternative based on process analysis and it is expected to offer the most representative results.

Regarding transport emissions, the results of the last two alternatives double those of HT_1 and HT_3, and the difference found with HT_2 is even larger (figure 3). It can be concluded that the last two alternatives overestimate the emissions of transport due to the use of Spanish data, while HT_1 underestimates the CF due to cut offs, and HT_2 due to the undervaluing of the Galician expenditures. Thus, HT_3 seems to offer the most representative results, being based on Galician data and reflecting the actual characteristics of the Galician economy.

The last comparison refers to the direct emissions, which correspond to fuel combustion in particular vehicles and households. In the last 4 alternatives, the direct emissions reflect Spanish conditions and the high variability found among them responds to the different years considered. Since direct emissions are not affected by cut-offs, HT_1 should offer the best results, especially since they have been obtained from Galician data when possible, unlike the remaining ones.

For the second group of consumption activities (FGS in figure 3), the three main contributing items in each category is shown inTable 3.

Table 3: Major contributors to the CF of food, goods and services in each alternative.

\begin{tabular}{|c|c|c|c|}
\hline Alt. & Food & Goods & Services \\
\hline 2 & $\begin{array}{l}\text { - Meat \& meat products } \\
\text { (43\%) } \\
\text { - Dairy products (15\%) } \\
\text { - Seafood }(5 \%)\end{array}$ & $\begin{array}{l}\text { - Petroleum refineries (29\%) } \\
\text { - Motor vehicles and parts ( } 15 \%) \\
\text { - Textile and leather products } \\
(10 \%)\end{array}$ & $\begin{array}{l}\text { - Food services \& drinking places } \\
(48 \%) \\
\text { - Automotive repair \& maintenance } \\
(10 \%) \\
\text { - } \text { Telecommunications }(7 \%)\end{array}$ \\
\hline 3 & $\begin{array}{l}\text { - } \text { Agriculture, livestock, } \\
\text { hunting \& related } \\
\text { activities (23\%) } \\
\text { - Meat products }(22 \%) \\
\text { - Dairy products }(19 \%)\end{array}$ & $\begin{array}{l}\text { - } \text { Manufacture of coke \& } \\
\text { petroleum products (44\%) } \\
\text { - } \text { Chemical \& pharmaceutical } \\
\text { products (14\%) } \\
\text { - } \\
\text { Motor vehicles (13\%) }\end{array}$ & $\begin{array}{l}\text { - Food and drinking services (42\%) } \\
\text { - Retailing (14\%) } \\
\text { - Wholesale }(11 \%)\end{array}$ \\
\hline
\end{tabular}




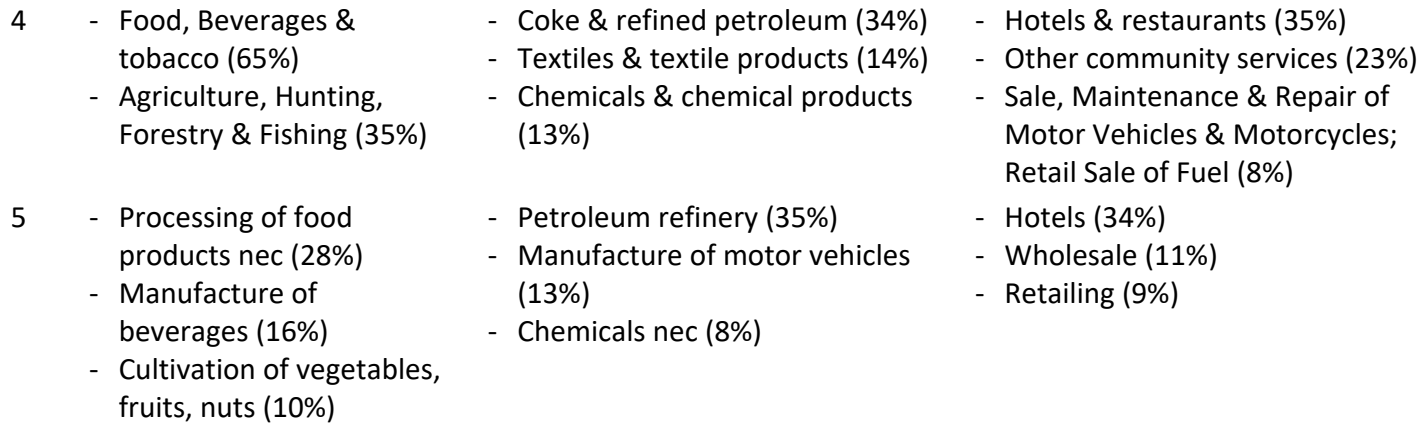

Regarding the CF of food consumption, the first three alternatives yield similar results, while those of FGS_5 are quite lower, which points at an underestimation of the emissions of the food category in FGS_5.

When comparing the CF of goods, all the alternatives point at the same main contributors (table 3): petroleum derivatives, textiles, vehicles and chemicals, although with variable contributions. In this case, the results of the last two alternatives are much higher than the first two, which can be explained by the use of MRIO databases, which are expected to be more accurate..

Finally, regarding the CF of the consumption of services, the last three alternatives yield much higher emissions than FGS_2 due to the lower expenditures considered there (table 1). Moreover, all the alternatives point at the same main contributor (hotels and restaurants). In the service sector, both MRIO approaches (FGS_4 and FGS_5) yield more representative results than the SRIO based ones, especially when the US EIO database is used.

\section{Carbon Footprint of production}

The CF of the Galician production activities has been determined following the alternatives defined in section 2.1.3, and the results have been split into the two major groups ( $P$ and $M$ ) defined there.

In PA based alternatives (P_1 and $M \_1$ ), the activity descriptors are physical quantities, while in EIO alternatives (M_2, P_3 and M_3) they are economic flows. Regarding the latter, the same economic data have been used for both alternatives M_2 and M_3.

As already mentioned in section 2.1.3, the use of alternatives considering different system boundaries (territory principle versus resident principle) may yield significant differences in the results. It is often not possible to identify the source of these differences: e.g. the CF of a multinational company having a site in Galicia may or may not be accounted for in the EIO based alternatives, depending on whether or not the economic flows of the site have been assigned to the region (i.e. included in the Galician EIO matrix). The data sources of this matrix are not detailed enough, so it is impossible to know which particular companies have been accounted for (with the exception of very large companies whose economic flows stand out and thus can be easily identified). When significant differences are found among the results shown in this section, explanations regarding which activities may have been excluded will be presented when available.

Figure 4 compares the results of the $P$ group evaluated with the 2 possible alternatives: $P$ _1 (based on process analysis) and P_3 (obtained from the Galician 10 matrix). 


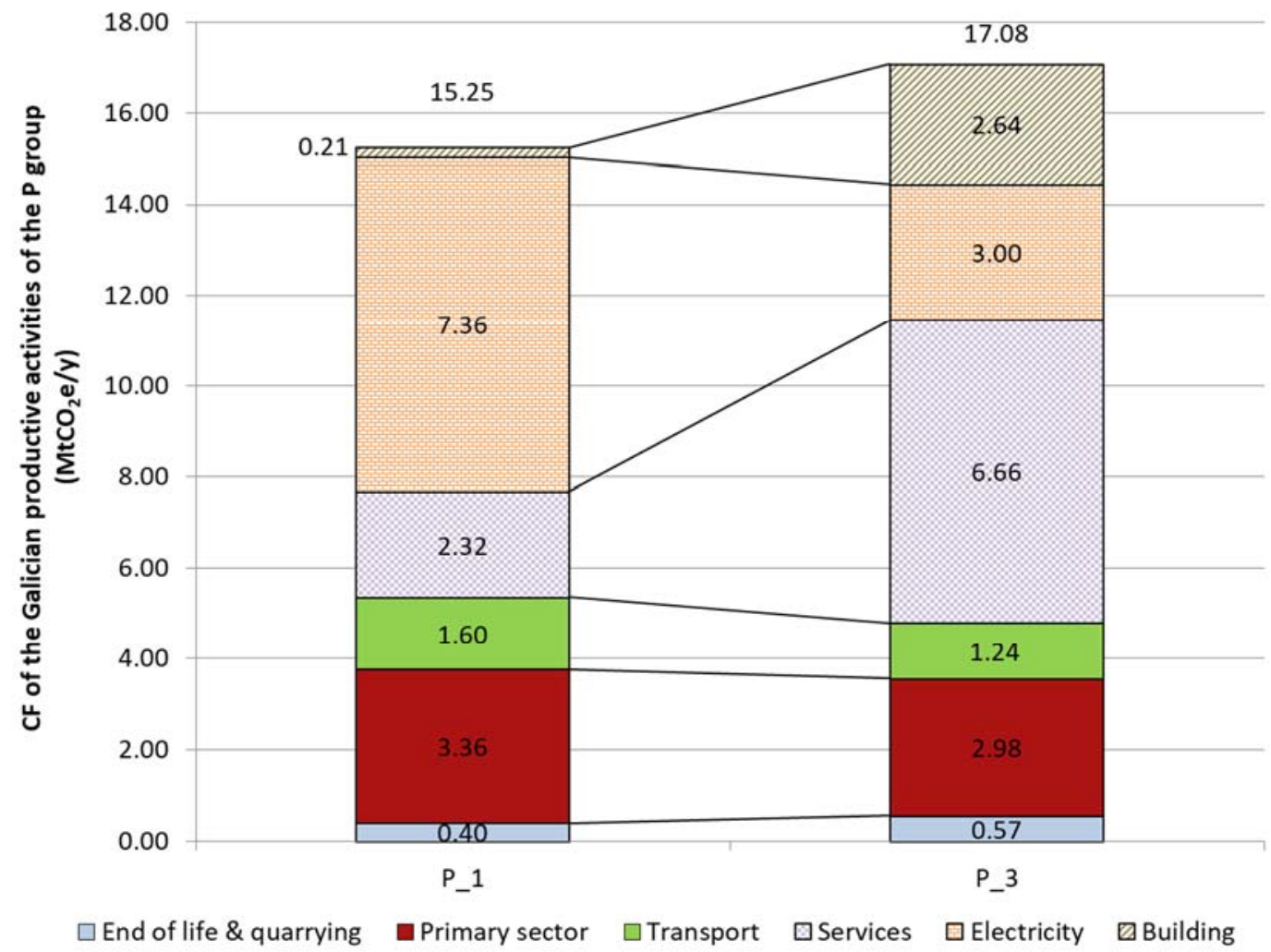

Figure 4: Carbon footprint of the Galician production activities included within the Production group.

The top-down alternative (P_3) computes higher $C F$ than the bottom-up one (P_1) (figure 4): $17.08 \mathrm{MtCO}_{2} \mathrm{e} / \mathrm{y}$ versus $15.25 \mathrm{MtCO}_{2} \mathrm{e} / \mathrm{y}$. The individual contributors of both alternatives are compared below:

- The most striking difference appears when comparing the CF of the services sector in both alternatives. The results offered by $P_{-} 3$ are expected to be more reliable, since those included in P_1 correspond to the consumption of heat, energy and water at the services sector plus the share of the remaining sectors which is purchased by the service sector. This procedure had to be followed due to the lack of data regarding the services sector in Spain, and the resulting figure is still incomplete (it excludes the CF of those products which are imported by the services sector).

- The CF of the primary sector is very similar in both alternatives, although the bottomup alternative $\left(P_{-} 1\right)$ yields higher results. This alternative is based on detailed Galician statistics of primary production, and the LCls are mainly taken from Galician studies, and so it is expected to be more representative of the actual emissions. P_3 offers a reasonably good approximation to the results of $P_{-} 1$, but it does not allow identifying the particular contributors to the $\mathrm{CF}$ of such a heterogeneous sector.

- The results of quarrying and EOL sectors have been grouped together, due to their low contribution to the final $\mathrm{CF}$ in both alternatives: the results of quarrying are very similar in both alternatives $\left(97 \mathrm{ktCO}_{2} \mathrm{e} / \mathrm{y}\right.$ in $\mathrm{P}_{-} 1 \mathrm{vs} .116 \mathrm{ktCO}_{2} \mathrm{e} / \mathrm{y}$ in $\left.\mathrm{P} \_3\right)$, while those of the EOL sector are higher in $\mathrm{P}_{-} 3\left(451 \mathrm{ktCO}_{2} \mathrm{e} / \mathrm{y}\right.$ vs. $303 \mathrm{ktCO}{ }_{2} \mathrm{e} / \mathrm{y}$ in $\left.\mathrm{P}_{-} 1\right)$. The differences can probably be explained by the cut offs inherent to the PA based alternative (P_1).

- The CF of electricity generation is much higher in $P \_1$ than in $P \_3$ due to the different system boundaries used in both approaches. The PA based alternative (P_1) follows the territory principle (i.e. it includes the emissions of the two thermal power plants physically located in the region), while the 10 based alternative ( $P_{-} 3$ ) follows the 
resident principle (i.e. it excludes them since they belong to large Spanish-based companies, whose economic benefits are not allocated to the region).

- When comparing the CF of the transport sector, the CF of alternative P_1 is higher than that of $P_{-} 3$, although the differences are not significant. Again, this variability can be explained by the different system boundaries considered: in the P_1 alternative physical limits have been set (only the transport distances covered within the boundaries of the region are accounted for), while P_3 starts from on the economic flows that the transport sector causes in the region.

- Last, the emissions of the building sector are much higher in P_3. This probably responds to an underestimation of the emissions of the bottom-up alternative, since only some infrastructures and buildings are accounted for there (see section S5 of the supplementary material), and thus the construction of numerous structures that are not included in the regional statistics are excluded. Moreover, the inventories used to characterize buildings are quite simplified.

Figure 5 compares the results of the $M$ group evaluated with the 3 possible alternatives. The CFs are split into the manufacturing activities which are responsible for the highest GHG emissions.

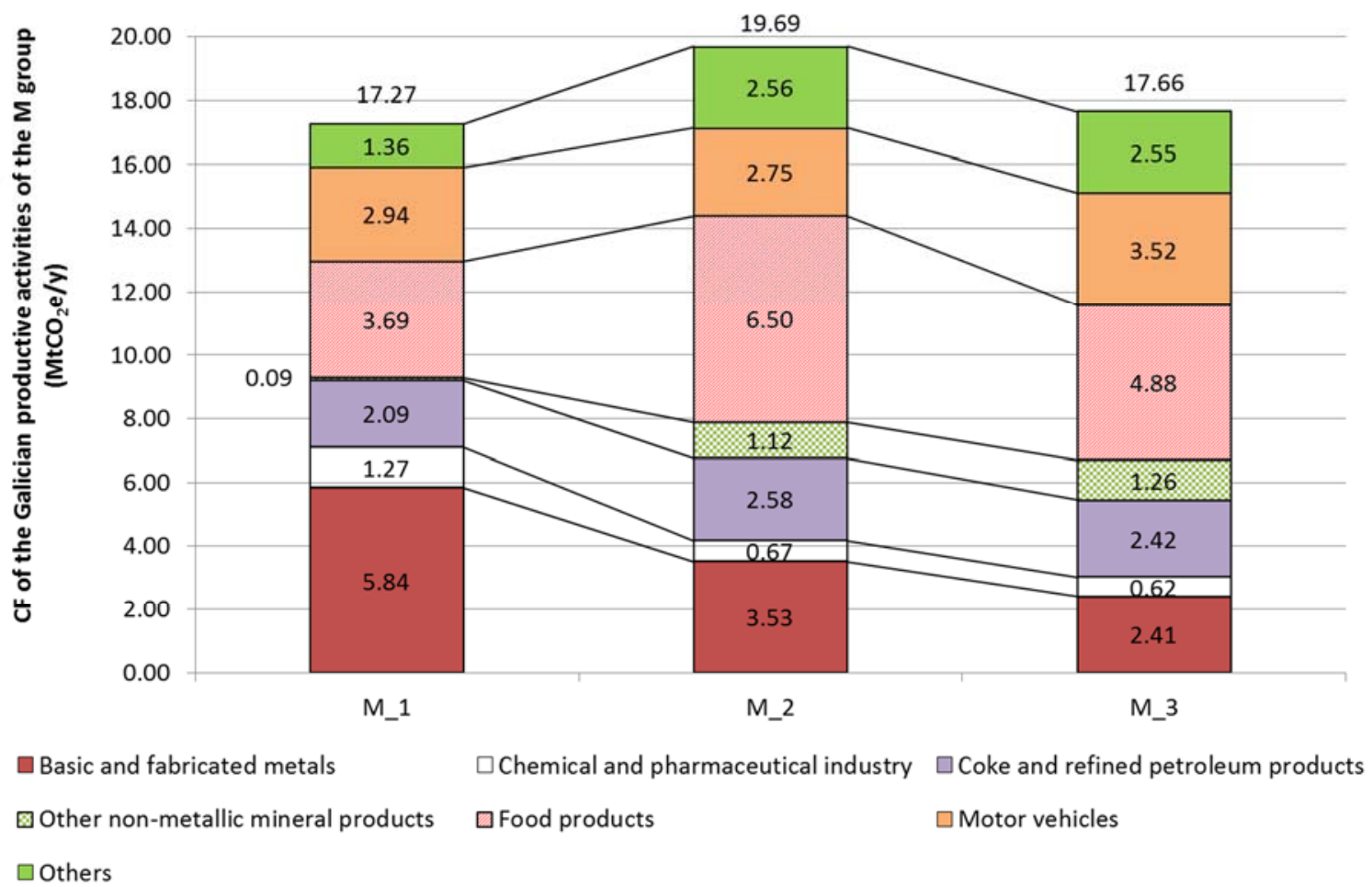

Figure 5: Carbon footprint of the Galician production activities included within the Manufacture group.

The results obtained with alternative $M \_1$, in which process analysis has been used, are lower than those of $M \_2$ and $M \_3$ for all the activities but two, i.e. basic and fabricated metal production and chemicals production (Figure 5). These lower results were expected, since not all the industries of the region are considered in M_1 but only those included in the EPRTR, and due to the cut-offs present in PA.

Thus, the differences found in the aforementioned two sectors, seem to respond to the different system boundaries considered: alternatives $M \_2$ and $M \_3$ probably exclude foreign companies located in Galicia whose emissions are accounted for in M_1.

Broadly speaking, when the total production of a certain sector is split among numerous small companies, alternative M_1 does not provide accurate results of its GHG emissions. This is the case of the food manufacturing sector, in which the CF obtained with alternatives M_2 and 
M_3 are much higher those that calculated with M_1. This responds to the presence of numerous small food processing companies in the region, which are not included in the Registry, in which only the facilities whose daily production exceeds certain thresholds are included. When comparing the results of $M_{-} 2$ and $M \_3$, the higher emissions of the former may respond to an overestimation of the GHG emissions in the 2002 US EIO database, which uses outdated US environmental data.

This is also the case of the manufacture of non-metallic mineral products (such as ceramics, tiles or concrete), performed by numerous small companies which are not included in the EPRTR. In this particular sector, the results are much higher in $M \_2$ and $M \_3$ than in $M_{-} 1$. The results of both 10 based alternatives are similar for this sector, although $M_{-} 3$ is expected to be more representative since it is based on the Galician IO matrix.

In the opposite case, i.e. in those sectors in which one large company is the major responsible for the CF, the results are more similar among the three alternatives. This is the case of petroleum refining and motor vehicle manufacturing. In the former, the results of the M_1 alternative are expected to be the most accurate ones, since they are based in the actual production of petroleum derivatives in the region, which is performed by only one company. However, M_1 results are probably affected by the cut-offs which are inherent to the bottomup alternatives, and thus the 10 based results (M_2 and M_3) are higher and still offer a good approximation to the actual situation. When focusing on motor vehicle manufacturing, the results of $M \_3$ are larger than those obtained with both $M \_1$ and $M \_2$. Again, $M \_3$ results are expected to be more accurate, since M_1 excludes the CF of the smaller companies (and suffers from cut-offs) while M_2 reflects the 2002 US technology, which may differ from the Spanish one reflected by M_3.

\section{Evaluation of alternatives}

The different alternatives proposed for the determination of the CF of the Galician consumption and production activities have been evaluated according to the criteria defined in section 2.2. A detailed table of the scoring of the reliability criterion is shown in section S9 of the supplementary material. And an overall score has been given here to each alternative (Table 4). 
Author-produced version of the article published in Journal of Environmental Management, 2018, ํ217, p.832-844. The original publication is available at https://www.sciencedirect.com/science/article/pii/S0301479718304213?via\%3Dihub Doi: 10.1016/j.jenvman.2018.04.039

Table 4: Multi criteria analysis of the five alternatives used to evaluate the CF of the household Galician consumption.

\begin{tabular}{|c|c|c|c|c|c|c|c|c|}
\hline Criteria & \multicolumn{2}{|l|}{ Subcriteria } & Weight & $\begin{array}{l}\text { Process } \\
\text { Analyisis } \\
\text { (ALT_1) }\end{array}$ & $\begin{array}{l}\text { US EIO } \\
\text { DB } \\
\text { (ALT_2) }\end{array}$ & $\begin{array}{c}\text { Galician } \\
\text { IO } \\
\text { matrix } \\
\text { (ALT_3) }\end{array}$ & $\begin{array}{l}\text { WORLD } \\
\text { IO DB } \\
\text { (ALT_4) }\end{array}$ & $\begin{array}{c}\text { Exiobase } \\
\text { IO DB } \\
\text { (ALT_5) }\end{array}$ \\
\hline Reliability & \multicolumn{2}{|l|}{ Of the results } & 1 & 2.5 & 1.0 & 2.0 & 3.0 & 2.0 \\
\hline \multirow{3}{*}{$\begin{array}{l}\text { Completenes } \\
\text { s }\end{array}$} & \multicolumn{2}{|c|}{ Of the activity descritptors } & 0.5 & 1.0 & 3.0 & 5.0 & 5.0 & 5.0 \\
\hline & \multirow[b]{2}{*}{ Of the LCls } & Matrix & 0.25 & 1.0 & 3.0 & 3.0 & 5.0 & 5.0 \\
\hline & & $\begin{array}{l}\text { Environmental } \\
\text { data }\end{array}$ & 0.25 & 5.0 & 5.0 & 4.0 & 3.0 & 3.0 \\
\hline \multirow{3}{*}{$\begin{array}{l}\text { Temporal } \\
\text { correlation }\end{array}$} & \multicolumn{2}{|c|}{ Of the activity descritptors } & 0.5 & 4.0 & 5.0 & 4.0 & 4.0 & 2.0 \\
\hline & \multirow[b]{2}{*}{ Of the LCls } & Matrix & 0.25 & 5.0 & 1.0 & 4.0 & 4.0 & 2.0 \\
\hline & & $\begin{array}{l}\text { Environmental } \\
\text { data }\end{array}$ & 0.25 & 5.0 & 1.0 & 4.0 & 3.0 & 2.0 \\
\hline \multirow{3}{*}{$\begin{array}{l}\text { Geographical } \\
\text { correlation }\end{array}$} & \multicolumn{2}{|c|}{ Of the activity descritptors } & 0.5 & 4.5 & 5.0 & 5.0 & 4.0 & 4.0 \\
\hline & \multirow[b]{2}{*}{ Of the $\mathrm{LCls}$} & Matrix & 0.25 & 3.0 & 1.0 & 5.0 & 4.0 & 4.0 \\
\hline & & $\begin{array}{l}\text { Environmental } \\
\text { data }\end{array}$ & 0.25 & 3.0 & 1.0 & 4.0 & 4.0 & 4.0 \\
\hline \multirow{5}{*}{ Applicability } & \multirow{4}{*}{$\begin{array}{l}\text { Of the } \\
\text { methodolog } \\
y\end{array}$} & $\begin{array}{l}\text { Data gathering } \\
\text { requirements }\end{array}$ & 0.125 & 1.0 & 5.0 & 5.0 & 5.0 & 5.0 \\
\hline & & \begin{tabular}{|l|} 
Software/trainin \\
g requirements
\end{tabular} & 0.125 & 3.0 & 3.0 & 5.0 & 5.0 & 1.0 \\
\hline & & $\begin{array}{l}\text { Economic } \\
\text { requirements }\end{array}$ & 0.125 & 1.0 & 1.0 & 5.0 & 5.0 & 5.0 \\
\hline & & $\begin{array}{l}\text { Calculation time } \\
\text { requirements }\end{array}$ & 0.125 & 5.0 & 2.0 & 4.0 & 3.0 & 1.0 \\
\hline & \multicolumn{2}{|c|}{ Of the results } & 0.5 & 5.0 & 4.0 & 2.0 & 1.0 & 3.0 \\
\hline Consistency & \multicolumn{2}{|c|}{ Of the methodology } & 1 & 3.0 & 3.0 & 5.0 & 5.0 & 5.0 \\
\hline & & TOTAL & - & 19.4 & 16.8 & 22.8 & 22.4 & 19.9 \\
\hline
\end{tabular}

The third alternative, based on the Galician 10 matrix obtains the highest global score, and thus it represents the best alternative to determine the CF of the Galician consumption and production. Alternative 4 (WIOD based) also obtains a high score, and thus it also represents a good option for the determination of the CF of Galician consumption, specially due to its multiregional character.

The carbon footprint of the consumption of a Galician inhabitant calculated with the best alternative has been presented in section 3.1 (alternatives HT_3 and FGS_3), while that of the Galician production was displayed in section 3.2 (alternatives $P_{-} 3$ and $M_{-}$) $)$. Both results were split there into two groups to facilitate comparison with the remaining alternatives. The total $\mathrm{CF}$ of Galician consumption reaches $5.90 \mathrm{tCO}_{2} \mathrm{e} /$ inhabitant/year $\left(16.48 \mathrm{MtCO}_{2} \mathrm{e} / \mathrm{y}\right)$, while that of the Galician production reaches $34.74 \mathrm{MtCO}_{2} \mathrm{e} / \mathrm{y}$. The detailed results are presented in section $\mathrm{S} 10$ of the supplementary material. It should be noted that both figures are very similar to those of the first study $\left(5.70 \mathrm{tCO}_{2} \mathrm{e} /\right.$ inhabitant/year and $34.90 \mathrm{MtCO}_{2} \mathrm{e} / \mathrm{y}$ (Roibás et al., 2017)), even though the contribution of the individual processes to the total figure is different in both methodologies.

\section{Evaluation of the proposed methodology and prospective improvements}

This section evaluates the proposed alternative (alternative 3, based on the Galician IO matrix) by presenting its main limitations, and proposing improvement measures for subsequent studies in the region. Last, the main advantages of the proposed method are summarized.

The major drawbacks of the proposed alternative, based on the Galician IO matrix, are the use of the Spanish environmental vector instead of the Galician one, and the fact that the Galician matrix is a SRIO matrix.

On the one hand, the environmental vector "B" (Eq.1 and 2) used was taken from the Spanish NAMEA air set, and thus it reflects the Spanish emissions of each sector per unit of monetary 
output, which were assumed equal to the Galician ones. NAMEA data is not available at the regional level, and thus this assumption was required.

The authors discarded to obtain a Galician vector of emissions from the data contained in the Galician GHG inventories (IGE, 2014), due to the different approaches used to compile both inventories (resident principle and territory principle) which makes the use of the Galician GHG inventories inconsistent with the 10 methodological framework. Moreover, the categories contained in both inventories are different from each other: the NAMEA account follows the NACE classification, while the UNFCCC data is split into Common Reporting Format (CRF) categories.

In summary, the Spanish NAMEA vector has been used because of being the best available option, but the authors acknowledge that having a proper Galician environmental vector would increase the accuracy of the results.

On the other hand, using single-region 10 tables implies the "domestic technology assumption". This assumption leads to inaccuracies of the results, since the environmental vector considered for Galicia can be very different from those of other countries from which the region imports goods, either due to different technologies used or due to the less severe environmental regulations.

In order to further evaluate the effect of this inherent characteristic of SRIO, the CF of the Spanish consumption has been evaluated using both SRIO and MRIO matrixes contained in WIOD (see section S11 of the supplementary material). In summary, using a SR matrix for Spain leads to an underestimation of $25 \%$ when compared to the use of a MR data. Peters and Hertwich (2006) found a $36 \%$ difference when comparing the CF of Norwegian consumption obtained with SR and MR approaches. Thus, significant underestimations are expected here for the Galician results.

Thus, among the prospective improvements proposed here, the development of a multi-region IO table for Galicia stands out. This matrix could be obtained by combining the MR matrixes contained in the World Input Output database with the Galician statistics for imports and exports. The creation of that matrix would improve the reliability of the aforementioned results, which were obtained by combining the best available data. The development of a Galician MRIO matrix would entail an important time and resources consumption (due to the large size of the WIOD matrix), and thus it is beyond the scope of this study. Other intermediate approaches, such as hybridization (i.e. combining Galician data for foreground emissions and MRIO data for background emissions), could also be considered.

It should be noted that only the CF indicator has been evaluated here, and that the recommended methodology is based on the determination of that indicator only. Thus, if a more complete life cycle assessment was performed to evaluate other environmental impacts, the methodologies would have to be re-evaluated to identify the best option, which may result in a different recommended methodology.

Among the advantages of the proposed methodology (based on the Galician 10 matrix) when compared to that used in our previous study (Roibás et al., 2017), the use of more recent and regional-specific data stands out, along with the much lower data requirement, which helps lowering the total calculation times and facilitates the replicability and updating of the study.

\section{Comparison to the consumption values in the literature}

During the review process of this article, a study evaluating the CF of the consumption of all European regions was published (Ivanova et al., 2017). Our results are compared to the Galician ones included in that study in section S12 of the supplementary material.

\section{Conclusions}

In this study, several methodological alternatives to calculate the carbon footprint of the consumption and production activities of a certain region have been proposed and compared. 
The objective was to improve the available results, computed with the territorial LCA methodology, but also to simplify that methodology, to increase its applicability and robustness in subsequent studies in Galicia or other regions of the world.

Different databases and procedures were evaluated, and it was concluded that the methodology based on the Galician input output tables was the most suitable one, and that it should be used in future studies, since the Galician 10 tables are updated on a periodical basis, and thus allow an easy updating of the results once the new tables are available. Moreover, this methodology can be applied to any region for which 10 tables and environmental vectors are available.

Last, the authors acknowledge that the calculation methodology proposed for Galicia can still be improved. This is due to the use of a SRIO database, which probably underestimates the CF embodied in imported products from less developed regions, and also to the use of a Spanish environmental vector, which may not reflect the actual Galician emissions. Thus, it has been concluded that converting the Galician SRIO matrix into a MRIO matrix, and developing a specific environmental vector for the region would improve the representativeness of the results, and thus subsequent efforts should be made in that direction.

\section{Acknowledgements}

This research did not receive any specific grant from funding agencies in the public, commercial, or not-for-profit sectors. This work was performed during a research stay of $\mathrm{L}$. Roibás at the ELSA Research Group for Environmental Lifecycle and Sustainability Assessment. L. Roibás and A. Hospido belong to Galician Competitive Research Group ED431C 2017/029 and to the CRETUS Strategic Partnership (AGRUP2015/02). All these programmes are cofunded by FEDER (UE).

\section{References}

Anaconda Software Distribution, 2016. Computer software. Vers. 2-2.4.0. Continuum Analytics Colomb, V., Amar, S.A., Mens, C.B., Gac, A., Gaillard, G., Koch, P., Mousset, J., Salou, T., Tailleur, A., van der Werf, H.M., 2015. AGRIBALYSE ${ }^{\circledR}$, the French LCI Database for agricultural products: high quality data for producers and environmental labelling, OCL, p. D104.

Eder, P., Narodoslawsky, M., 1999. What environmental pressures are a region's industries responsible for? A method of analysis with descriptive indices and input-output models. Ecol. Econ. 29, 359-374.

Eurostat, 2008. NACE Rev. 2-statistical classification of economic activities in the European Community. $\quad$ http://ec.europa.eu/eurostat/documents/3859598/5902521/KS-RA-07-015EN.PDF (accessed 25.04.2016).

Eurostat, 2016. Greenhouse gas emissions by industries and households. http://ec.europa.eu/eurostat/statistics-

explained/index.php/Greenhouse gas emissions by industries and households (accessed 03.04.2017).

Eurostat, 2017. Bovine population - annual data. http://ec.europa.eu/eurostat/statisticsexplained/index.php/Agricultural production - animals (accessed 17/12/2017).

Gallego, A., Hospido, A., Moreira, M., Feijoo, G., 2009. Quantification of eutrophic aerial compounds in Galicia (NW Spain): Part 1-NH3 inventory. Atmosfera 22, 141-160.

Hawkins, E., Ortega, P., Suckling, E., Schurer, A., Hegerl, G., Jones, P., Joshi, M., Osborn, T.J., Masson-Delmotte, V., Mignot, J., 2017. Estimating changes in global temperature since the pre-industrial period. Bulletin of the American Meteorological Society.

IGE, 2011. Marco Input Output de Galicia 2011: Matriz simétrica da produción interior a prezos

básicos. 
Author-produced version of the article published in Journal of Environmental Management, 2018, N²17, p.832-844. The original publication is available at https://www.sciencedirect.com/science/article/pii/S0301479718304213?via\%3Dihub Doi: 10.1016/j.jenvman.2018.04.039

http://www.ige.eu/web/mostrar actividade estatistica.jsp?idioma=es\&codigo=0307007003 (accessed 07.03.2016).

IGE, 2014. Emisións de gases de efecto invernadoiro por categoría de actividade. http://www.ige.eu/igebdt/esqv.jsp?ruta=verTabla.jsp?OP=1\&B=1\&M=\&COD=6883\&R=1[2011: 2012:2013];0[all]\&C=2[all]\&F=\&S=998:12\&SCF= (accessed 29.09.2016).

IGE, 2015. Número de bovinos por clase. Galicia e provincias. Ano 2014. https://www.ige.eu/igebdt/esqv.jsp?paxina $=001 \& \mathrm{c}=0301005 \&$ ruta $=v e r P p a l e s R e s u l t a d o s . j s p ?$ $\mathrm{OP}=1 \& \mathrm{~B}=1 \& \mathrm{M}=\& \mathrm{COD}=2917 \& \mathrm{R}=1[1: 2: 4: 5: 3] \& \mathrm{C}=9912[\mathrm{all}] \& \mathrm{~F}=\mathrm{T}[1: 0] ; 2: 1 ; 3: 11 \& \mathrm{~S}=\& \mathrm{TI}=3$ (accessed 17/12/2017).

IGE, 2017. Matriz simétrica (in Galician). http://www.ige.eu/estatico/html/gl/economicas/contas/input output/2011/Matriz Simetrica MIOGAL11.xIsx (accessed 16/01/2018).

INE, 2014. Gasto total y gastos medios de los hogares. http://www.ine.es/jaxiT3/Datos.htm?t=10724 (accessed 03.03.2016).

INE, 2016a. Contabilidad Nacional Anual de España. Base 2010. Tablas de Origen y Destino 2012. . http://www.ine.es/jaxi/menu.do?type=pcaxis\&path=\%2Ft35\%2Fp008\&file=inebase (accessed 25.11.2016).

INE, 2016b. Cuentas de emisiones a la atmósfera. Base 2010. Serie 2008-2014. http://www.ine.es/jaxi/Tabla.htm?path=/t26/p084/base 2010/serie/l0/\&file=01001.px\&L=0 (accessed 25.11.2016).

IPCC, 2013. Summary for Policymakers, Climate Change 2013: The Physical Science Basis. Contribution of Working Group I to the Fifth Assessment Report of the Intergovernmental Panel on Climate Change. [Stocker,T.F., D. Qin, G.-K. Plattner, M. Tignor, S.K. Allen, J. Boschung, A. Nauels, Y. Xia, V. Bex and P.M. Midgley (eds.)]. Cambridge University Press, Cambridge, United Kingdom and New York, NY, USA.

Ivanova, D., Vita, G., Steen-Olsen, K., Stadler, K., Melo, P.C., Wood, R., Hertwich, E.G., 2017. Mapping the carbon footprint of EU regions. Environ. Res. Lett. 12, 054013.

Lenzen, M., 2008. Double-Counting in Life Cycle Calculations. J. Ind. Ecol. 12, 583-599.

Leontief, W.W., 1951. The structure of American economy, 1919-1939: an empirical application of equilibrium analysis.

Loiseau, E., Junqua, G., Roux, P., Bellon-Maurel, V., 2012. Environmental assessment of a territory: An overview of existing tools and methods. J. Environ. Manage. 112, 213-225.

Loiseau, E., Roux, P., Junqua, G., Maurel, P., Bellon-Maurel, V., 2013. Adapting the LCA framework to environmental assessment in land planning. Int. J. Life Cycle Assess. 18, 15331548.

MAGRAMA, 2016. Información por Comunidad Autónoma. Galicia. http://www.adaptecca.es/administracion-autonomica-local/comunidades-

autonomas/ccaa?field ccaa value $=12$ (accessed 25.04.2016).

Peters, G.P., 2008. From production-based to consumption-based national emission inventories. Ecol. Econ. 65, 13-23.

Peters, G.P., Hertwich, E.G., 2006. Pollution embodied in trade: The Norwegian case. Global Environ. Change 16, 379-387.

PRTR España, 2015. Registro Estatal de Emisiones y Fuentes Contaminantes. http://www.prtres.es/ (accessed 05.10.2015).

REE, 2014. El sistema eléctrico español. http://www.ree.es/es/publicaciones/sistema-electricoespanol/informe-anual/informe-del-sistema-electrico-espanol-2014 (accessed 07.03.2016).

Roibás, L., Loiseau, E., Hospido, A., 2017. Determination of the carbon footprint of all Galician production and consumption activities: Lessons learnt and guidelines for policymakers. J. Environ. Manage. 198, Part 1, 289-299.

Suh, S., 2010. CEDA 4.0 User's Guide. https://www.presustainability.com/download/manuals/CEDAUsersGuide.pdf (accessed 03.03.2016). 
Timmer, M.P., Dietzenbacher, E., Los, B., Stehrer, R., Vries, G.J., 2015. An illustrated user guide to the world input-output database: the case of global automotive production. Rev. Int. Econ. 23, 575-605.

Tukker, A., de Koning, A., Wood, R., Hawkins, T., Lutter, S., Acosta, J., Rueda Cantuche, J.M., Bouwmeester, M., Oosterhaven, J., Drosdowski, T., Kuenen, J., 2013. EXIOPOL - DEVELOPMENT AND ILLUSTRATIVE ANALYSES OF A DETAILED GLOBAL MR EE SUT/IOT. Econ. Systems Res. 25, 50-70.

United Nations, 2015. Adoption of the Paris agreement. https://unfccc.int/resource/docs/2015/cop21/eng/l09r01.pdf (accessed 13/04/2016).

Weidema, B.P., Thrane, M., Christensen, P., Schmidt, J., Løkke, S., 2008. Carbon Footprint. J. Ind. Ecol. 12, 3-6.

Weidema, B.P., Wesnæs, M.S., 1996. Data quality management for life cycle inventories-an example of using data quality indicators. J. Clean. Prod. 4, 167-174.

Weidema, B.P.B., Ch.; Hischier, R.; Mutel, Ch.; Nemecek, T.; Reinhard, J.; Vadenbo, C.O.; Wernet, G, , 2013. The ecoinvent database: Overview and methodology, Data quality guidelines for the ecoinvent database version 3, www.ecoinvent.org.

Wernet, G., Bauer, C., Steubing, B., Reinhard, J., Moreno-Ruiz, E., Weidema, B., 2016. The ecoinvent database version 3 (part I): overview and methodology. Int. J. Life Cycle Assess. 21(9), 1218-1230.

Wiedmann, T., 2009a. EDITORIAL: CARBON FOOTPRINT AND INPUT-OUTPUT ANALYSIS - AN INTRODUCTION. Econ. Systems Res. 21, 175-186.

Wiedmann, T., 2009b. A review of recent multi-region input-output models used for consumption-based emission and resource accounting. Ecol. Econ. 69, 211-222.

WIOD, 2013a. Environmental Accounts. Emissions to air. http://www.wiod.org/database/eas13 (accessed 16/01/2018).

WIOD, 2013b. World Input-Output Tables. http://www.wiod.org/protected3/data13/update sep12/wiot/wiot11 row sep12.xlsx (accessed 16/01/2018).

Wood, R., Stadler, K., Bulavskaya, T., Lutter, S., Giljum, S., de Koning, A., Kuenen, J., Schütz, H., Acosta-Fernández, J., Usubiaga, A., Simas, M., Ivanova, O., Weinzettel, J., Schmidt, J.H., Merciai, S., Tukker, A., 2015. Global sustainability accounting-developing EXIOBASE for multiregional footprint analysis. Sustainability (Switzerland) 7, 138-163.

Xunta de Galicia, 2016. Informe de Cambio Climático de Galicia 2012-2015. http://cambioclimatico.xunta.gal/c/document library/get file?file path=/portal-cambioclimatico/Documentos xeral/INFORMECC2.pdf (accessed 16.11.2016). 